\title{
NORTHLAND LAND DEVELOPMENT
}

\author{
R. K. Somerville \\ Superintendent of Land Development, Lands and Survey \\ Department, Whangarei
}

THE development of virgin country for farming by the Lands and Survey Department started in New Zealand nearly forty years ago. From modest beginnings, when taken over in the early thirties from the Department of Agriculture, and with increasing experience through the years, the work has been greatly accelerated. Today, it is widespread in both islands on such a scale that, in total, it represents the largest farm development ever undertaken in the history of New Zealand.

In spite of its size and cost, this large national undertaking is self supporting. The initial costs of acquiring land, the breaking-in and conversion of it to commercial farming are found by the State. The financial return from the farming of the many Land Development blocks and ultimate subdivision and sale to new settlers pays for the whole undertaking and it therefore does not become a burden on the taxpayer. The Lands and Survey Department also undertake, by agreement,.the development of some of the virgin land under the jurisdiction of the Department of Maori Affairs.

In the late $1940 \mathrm{~s}$, the Department turned its attention to the very large areas of idle and semi-idle land in N orthland. Much of this was in its native state, covered with bush, scrub, fern and second growth. A considerable area had been repeatedly burnt off and was full of weeds such as gorse, blackberry and rushes. Many of these idle areas were regarded as third-class land, thought to be of little if any value for farming, and too difficult and costly to develop.

No land development on the scale planned by the Department had ever been attempted before in N orthland. Initially, there was little information available about the best methods of clearing, cultivation, or weed control, the correct quantities of lime, fertilizer and trace elements needed, the most suitable pasture mixtures to sow, the possibilities of cropping, availability of water supplies, cost of fencing, the class of motive power needed for many 
operations, or the many other requirements and practices that are essential parts of any large-scale land development project. It would be true to say that, 20 years ago, Northland was almost a virgin field to exploit.

Why then did the Department wish to tackle these Northland areas? It was known that the climate of Northland was ideal for grassland farming. The rainfall was adequate and reasonably well spread: the temperature throughout the year, moderate. The soils had been mapped by the Soil Bureau and this work had focused attention on the farming potential of these idle lands of the north.

The topography of much of the undeveloped land did not present any insuperable difficulties for development. The experimental farm in Northern Wairoa had shown a measured yield from a mixed permanent pasture of over 19,000 lb dry matter per acre — the highest yield from pasture recorded in New Zealand at that time.

Northland could not possibly be excluded from the National Land Development Scheme. So it was that, before 1952, and with experience based mainly on land development in the Rotorua area! work was commenced on the Kokopu, Punakitere, Kapiro, Okahukura and Omaranui blocks -a total area' of 74,600 acres.

It was soon found that the soils of $\mathrm{N}$ orthland were entirely different in every respect from the young pumice soils of the Central Plateau. New and revolutionary methods of soil clearing, cultivation and treatment had to be designed. The six blocks mentioned were the experimental areas from which much was learned, including the problems of cultivation, scrub regrowth and rush control and the best time for this work to be carried out.

In the immediate post-war years, when Northland Iand development was first undertaken on a sizable scale, generous help in solving problems was given by the few advisory officers of the Department of Agriculture then stationed in Northland. Reports and maps of the Soil Bureau proved invaluable. But it was after 1957, only 10 years ago, that the real breakthrough took place. The accumulated experience gained from earlier work, the appointment of more advisory officers in Northland, closer and more detailed co-operation with these officers, the "crash" programme advocated by the late Dr Peter Sears, and the establishment, in 1955, of the Grasslands Research Station at Kaikohe have all played a vital part in land development work in Northland from 1957 to the present day. 
The managers and field officers of the different blocks became the key men in the undertaking; their ability, enthusiasm and loyalty meant much to the success of the project. While per-acre production was laid down as the critical "yard stick", the unique mozaic soil pattern of Northland meant that practically every block was different. Not only had extreme variations in land development work to be considered - similar variations applied to all other factors including stocking and the classes of stock needed at different periods through the year. The only constant factor was that, with many of the earlier problems overcome, all soils on these development blocks in Northland could grow good pasture if the treatment of the soils, management, and utilization of the feed were handled competently. This called for a high degree of skill from field officers and block managers.

In the development of this virgin land for farming, many new techniques have been employed successfully. However, the success of the work, in every case, has depended primarily on the employment of the principles and techniques of good husbandry in cultivation work, soil treatment and management, stock work and pasture utilization, good stock, well fed all the year round, the value and proper use of time and the recognition of the human factor and its employment. New developments have not superseded the importance of any of these factors, but they have made for greater efficiency in all branches of the work.

\section{DEVELOPMENT METHODS}

As mentioned earlier, the initial results of establishing pastures were based on experience in the Rotorua area. These proved entirely inadequate. It was found that initial good strikes of grass slumped after 2 to 3 years. Following work on the Kaikohe Research Station in 19574, ideas on the use of lime and fertilizer were completely revised. It has been proved beyond doubt that the first requirement on the bulk of the northern soils is massive initial doses of lime and fertilizer to quickly establish a good sward of clovers and grasses. A good cover of pasture is essential both to recoup costs and to control weeds, such as gorse, rush and manuka. Good cultivation is necessary, and, in the main, the practice is to fallow newly-cultivated soils for 2 years. This, together with thorough subsequent cultivation, leaves the soil in a condition where a good surface and seedbed result. 
The liming programme is standard at 2 tons per acre on most of the clays and the Te Kopuru soils. For volcanic soils, sands, sandstone and more friable clays, 1 ton appears adequate particularly where molybdenum response can be expected. Fertilizer is applied at the rate of 6 cwt per acre of superphosphate together with molybdenum where needed at the time of sowing down. In the spring, $6 \mathrm{cwt}$ of $15 \%$ potassic superphosphate is applied and a further $3 \mathrm{cwt}$ of superphosphate in the following autumn. Altogether, new pastures receive either 1 or 2 tons of lime plus $14 \mathrm{cwt}$ of fertilizer in the first 12 months. Copper is also necessary on some soils and appears to give a pasture response on some clay soils apart from the stock health consideration.

For maintenance of pasture, an average of $3 \mathrm{cwt}$ of fertilizer per acre is applied (in most cases, this contains $15 \%$ potash and molybdenum where desirable), together with $1 / 2$ ton of lime every second or third year dependent on the soil type and whether or not there is molybdenum response. Molybdenum is proving to be an essential part of the establishment and maintenance of Northland pastures and more information is needed about this element. It will not, however, entirely replace lime on the bulk of the northern soils. In most cases, their functions are complementary, not only in establishing and maintaining good pasture, but from the point of view of stock health. Figures quoted later confirm this.

Weeds, such as gorse and rush, have proved major problems and expensive items in development activities. Gorse can be controlled by hormones, but this method is expensive. There is no return from money expended on 2,4,5-T, considerable pasture damage results from spraying, and the loss of revenue is considerable. Some progress in rush control has been made recently by a combination of rotary mowing and spraying, and also by mowing and set-stocking the area with approximately 10 to 12 wethers to the acre. The latter method shows considerable promise and if it proves economical will be adopted.

To cope with more difficult contours - inevitable as new land becomes available for development - a technique of burning and surface sowing has been developed. In most cases, this land is covered with manuka and hakea. This is burnt standing. Lime, fertilizer and seed are then sown by plane. Some of the advantages of this method are as follows :

The cost of cultivation or cutting is obviated, which constitutes a saving of approximately $\$ 20$ to $\$ 24$ per acre. 
The total area is grassed ; there are no ungrassed steep areas left which are al ways a problem to deal with later.

There are few rush problems compared with those on wet clays when cultivated.

The original consolidation of the soil is not disturbed and, of course, soil conservation problems are considerably fewer.

Any surface fertility is retained.

The benefits of the ash from the burn are not lost.

It has been found that surface sown areas stand up to drought conditions considerably better than do cultivated areas, perhaps because of better consolidation.

The lime and fertilizer programme on these surface-sown areas is the same as that described earlier.

This method calls for a high degree of livestock and pasture management by block managers as the seedling growth of manuka, etc., which follows must be controlled for the first 2 to 3 years. Close subdivision is essential to enable quick concentration of stock to deal with weed growth.

From experience, it has been found that adult wethers are the most suitable stock for the initial seedling scrub control. The objective is to keep the scrub down to about 3 to 4 in., and, provided wethers are concentrated at about 20 to the acre, it is surprising the control that can be established. Where scrub gets beyond this height, cattle are required, and, when clovers and grasses have been lush, they appear to relish roughage after a soft diet. Cattle seem to eat scrub topdressed with molybdenum more readily, possibly because molybdenum makes manuka more palatable.

Two seed mixtures are used - A and C. A is used on cultivated and surface sown areas and $C$ for the renovation of run-out pasture. These mixtures are made up as follows:

Mixture A: $15 \mathrm{lb}$ perennial ryegrass; $5 \mathrm{lb}$ short rotation ryegrass ; $5 \mathrm{lb}$ cocksfoot ; $3 \mathrm{lb}$ white clover ; $1 \mathrm{lb}$ Mt Barker subterranean clover; 2 lb timothy; 1 lb crested dogstail total $32 \mathrm{lb}$ per acre.

Mixture C: $10 \mathrm{lb}$ perennial ryegrass ; $1 \mathrm{lb}$ Mt Barker subterranean clover; $2 \mathrm{lb}$ white clover - total $13 \mathrm{lb}$ per acre.

All clover seed used is now inoculated triple-coated. Total clovers have been reduced by leaving out red clover. The ryegrass content has been increased to overcome to some degree the problem of clover dominance in the early years. 
The seed is sown by roller seed box combination on cultivated land and by plane on the steeper country.

A considerable problem exists on some soils regarding the quick establishment and maintenance of clovers. The early endeavours to inoculate seed were disappointing, mainly because of the large areas involved and the difficulty in handling the inoculant correctly. Since the advent of inoculated triple-coated seed, spectacular results have been obtained and this factor has been of considerable importance on some soils, particularly the Houhora sands.

Since this improved establishment of clovers, some trouble has been experienced with the fertility of female stock and it is thought that this may be the result of the high oestrogen content of the clovers, particularly red clover. It has been significant that, as the grasses establish with the rise in soil fertility, lambing and calving percentages improve.

\section{LIVESTOCK QUALITY}

The myth that Northland is not capable of growing quality sheep and cattle has' been completely discredited. With the vast improvement in pastures and the use of quality sires, both cattle and sheep have improved beyond recognition, dairy and beef cattle in particular. An example of the excellent stock raised in Northland was illustrated at recent beef competitions at the Waikato Winter Show when cattle from Lands and Survey blocks were placed first on the hoof and second on the hooks.

The following figures illustrate that the techniques outlined have resulted in reasonable production progress on the areas developed and farmed in Northland by the Land Development Branch.

Sheep numbers have risen from 185,000 in 1962, to 368,000 in 1967 (approximately 100\% increase). In 1962, cattle numbered 27,000, and, in 1967, 46,000 (approximately $70 \%$ increase). Ewe equivalents per acre have increased from 2.51 in 1962 to 4.55 in 1967.

The remarkable feature of this increase is that the total area grassed has remained the same at approximately 100,000 acres. There has been no increase in this period in the rate of fertilizer used per acre. It has remained constant at approximately $3 \mathrm{cwt}$. It is considered that this improve ment has been brought about by the programme of adequate lime maintenance and more use of molybdenum described earlier, and by making the best use of the fertilizer applied by improved pasture utilization. It is essential in 
the acid soils of the north to maintain a soil $\mathrm{pH}$ level of at least 5.8 with lime to obtain the best use of fertilizer.

Some idea of the production from the 100,000 acres of pasture being farmed at present may be gained from the budget figure, for the current year, of approximately $\$ 3,000,000$ gross revenue, of which $\$ 350,000$ is from transfers but which would, in normal circumstances, be sales. It will be appreciated, therefore, the impact land development must have on N orthland as a whole. It is estimated that the Land Development blocks will produce $3,500,000 \mathrm{lb}$ of wool this season, or approximately 10,000 bales.

The purpose in developing this land is the settlement of young men and, since the inception of the scheme, approximately 332 men have been settled in the Northland Land Development District which stretches from Mercer to the North Cape. This of course means a tremendous amount of planning and work in the way of buildings, fences, water supply and electric power reticulation, etc. All this work is performed by contractors under the direction of departmental sections which design the projects, call tenders, let contracts and supervise the work. The Survey Branch co-operates with the Land Development and Land Settlement Committees in the planning and subdivision of the blocks into suitable units for settlement.

The total area currently handled, including Maori blocks, is 284,670 acres of which approximately 100,000 acres are in grass. It is estimated that this land will eventually produce 473 units. There are 41 managers and a total of 130 farm staff employed.

In conclusion, it is fitting that a tribute be paid to the vision of a retired Director-General of Lands, D. M. Greig (1946-58), who was the architect of the Land Development Branch as it has been known of recent years, and to succeeding Directors-General whose moral and financial support have contributed in such large measure to the success of land development in Northland.

\section{DISCUSSION}

The Lands and Survey Department is achieving its production increase at $0.7 \mathrm{cwt}$ fertilizer per ewe equivalent, as opposed to 1.7 to $2.2 \mathrm{cwt}$ on other farms. Would Mr Somerville comment?

The $0.7 \mathrm{cwt}$ per ewe equivalent refers to fertilizer only, and as we have a policy of using approximately $\frac{1}{2}$ ton of lime every second or third year on most of our pastures, the cost of this should be included. The figure would then be nearcr, say, $1.25 \mathrm{cwt}$ per ewe equivalent. 
Did the oestrogen trouble coincide with the use of molybdenum?

No. It is of significance, however, that as fertility rises and we obtain a better balance of grasses to clover, so our lambing percentages improve.

Red clover has now been excluded from the seed mixture. Has this made any difference to fhe oestrogen problem?

The non-use of red clover is so recent that I am not in a position to comment on this point at the moment.

What is the value of subterranean clover in the mixture? Are there very light soils involved?

Subterranean clover has some value on the poor soils but with the amount of initial lime and fertilizer used there is now no problem of establishing a good initial cover of white clover. Therefore, to my mind, subterranean clover loses its value as an initial provider of nitrogen.

\section{A re there any plans for the use of A riki ryegrass in the mixtures?}

To date, we have not made use of this strain but intend doing so in the future.

The key to success is the rate af which stock numbers can be built up. How did Lands and Survey Department build up so quickly, and has the peranimal yield deteriorated7

By increasing our breeding flocks and herds to the maximum and by outside purchase of breeding stock.

Yes, as our stocking rates have been built up, the individual performances of the animals have fallen off, but, of course, meat and wool per acre has increased considerably.

\section{What part has field drainage played in this development?}

We do a considerable amount of surface drainage on the wet soils, such as the Wharekohe type, wherc, owing to the nature of the soils, there is no sub-drainage. This problem is taken care of by contour banks constructed to shed the surplus water. This is proving very helpful and is enabling us to utilize these areas to better advantage during the wet months, 